\title{
A configuração do trabalho da enfermeira na atenção ao idoso na Estratégia de Saúde da Família
}

\author{
The configuration of the work of nurses in care of the elderly \\ in the Family Healthcare Strategy
}

Gleide Magali Lemos Pinheiro ${ }^{1}$

Angela Maria Alvarez ${ }^{2}$

Denise Elvira Pires de Pires ${ }^{2}$

\footnotetext{
${ }^{1}$ Departamento de Saúde, Campus de Jequié, Universidade Estadual do Sudoeste da Bahia. Rua José Moreira Sobrinho S/N, Jequiezinho. 45200-000 Jequie BA.

gleidemlp@gmail.com ${ }^{2}$ Departamento de Enfermagem, Centro de Ciências da Saúde, Universidade Federal de Santa Catarina.
}

\begin{abstract}
The scope of this article was to describe the configuration of the work of nurses with the elderly within the Family Healthcare Strategy, highlighting the actions in which their activities are concentrated. It involved an exploratory-descriptive study of a qualitative nature, in which the informants were nurses working in the FHS in Florianópolis in the state of Santa Catarina. Data were collected through narrative interviews and the results were subjected to content analysis, resulting in three thematic categories and their subcategories: individual care: nursing consultation with the elderly; collective care: working in groups; home care: the visit as the scope of activity. The results revealed that the work of nurses in promoting the health of the elderly in the FHS is being structured in accordance with the dayto-day demands that arise in the population, resulting in some contradictions regarding the current model of care. This situation leads to the challenge of reviewing practices and rethinking ways of working to care for the elderly, striving to develop tools and methodologies based on politically and socially established know-how in order to gain and demarcate their sphere of action in the field of health.
\end{abstract}

Key words Health of the elderly, Health promotion, Family Healthcare Program, Community health nursing
Resumo Este artigo teve como objetivo descrever a configuração do trabalho da enfermeira com o idoso na Estratégia de Saúde da Família (ESF), destacando as ações nas quais se concentram a sua atuação. Caracterizou-se como um estudo exploratório-descritivo de natureza qualitativa que teve como informantes enfermeiras que atuam na ESF do município de Florianópolis/SC. As informações foram coletadas por meio da entrevista narrativa e os resultados foram submetidos à técnica de Análise de Conteúdo, originando três categorias temáticas e suas respectivas subcategorias: O cuidado individual: a consulta de enfermagem com o idoso; O cuidado coletivo: a atuação em grupos; e, O Cuidado no domicílio: a visita como espaço de atuação. Os resultados mostram que o trabalho da enfermeira na promoção da saúde do idoso na ESF vem estruturando-se com as demandas que emergem no cotidiano da população, apresentando algumas contradições em relação ao modelo de atenção em curso, situação que a coloca diante do desafio de revisar suas práticas e repensar os modos de operar o trabalho na atenção ao idoso, com vistas a desenvolver instrumentos e metodologias fundamentados em conhecimentos politicos e socialmente instituídos no intuito de conquistar e demarcar seu espaço de atuação no campo da saúde coletiva.

Palavras-chave Saúde do idoso, Promoção da Saúde, Programa de Saúde da Família, Enfermagem 


\section{Introdução}

Os debates políticos ao longo da década de 1980 deram origem a importantes acontecimentos no cotidiano do povo brasileiro, com significativas repercussões nos setores sociais. No campo da saúde, o movimento pela Reforma Sanitária Brasileira (RSB) e a promulgação da Constituição Federal de 1988, que criou o Sistema Único de Saúde (SUS), garantiram a todo cidadão brasileiro o livre acesso às ações de saúde em níveis de promoção, proteção, recuperação e reabilitação ${ }^{1,2}$.

Gestado no âmbito da RSB, O SUS caracteriza-se como um avanço para o setor da saúde ao propor a materialização de ações que concorrem para o resgate da cidadania do povo brasileiro, por meio de práticas fundamentadas nos princípios da Universalidade, da Integralidade, da Equidade, da Resolutividade e da Participação Social.

Dada a sua importância no cenário da saúde, a RSB é considerada importante fato no campo social, por indicar possibilidades de mudanças no modelo de atenção com base em ideais democratizantes e inclusivos com vistas a alcançar a equidade entre as diversas classes populacionais. Esse novo modelo trouxe como novidades a criação de um sistema nacional de saúde, a descentralização da gestão do sistema com a ampliação do conceito de gestão, incluindo a participação dos prestadores, trabalhadores, gestores e usuários, e a reformulação da atenção à saúde com base na superação das ações individuais centradas na doença, com amplas modificações nas práticas profissionais ${ }^{3}$.

Com essas mudanças, a sociedade brasileira passou a conviver com dois fatos que influenciaram o panorama da saúde: as mudanças na pirâmide etária - na qual se vem observando significativa redução das taxas de fecundidade e de natalidade, resultando na diminuição da população jovem e no aumento da população idosa e a transição epidemiológica - que passou a apresentar forte predomínio das doenças crônicodegenerativas, demandando intervenções contínuas e superespecializadas, onerando sobremaneira o sistema de saúde.

A transição epidemiológica caminhou e caminha junto com o envelhecimento populacional. $\mathrm{O}$ fato de se conviver com uma multiplicidade de problemas, que cada vez mais exigem intervenções especializadas, e, consequentemente, oneram os cofres públicos, conduziu à necessidade de políticas públicas com enfoque mais preventivo, sem se distanciar do tratamento e da reabilitação.
Com a criação das leis que regulamentam o SUS, a Lei 8.080, a Lei Orgânica da Saúde e a Lei 8.142, que trata das questões relativas ao Controle Social, o SUS começou a ser implementado e, a partir daí, o Ministério da Saúde (MS) deu início à publicação de uma série de atos administrativos em forma de portarias, decretos, resoluções e normas, como instrumentos de regulação do sistema de saúde, cujo objetivo principal é regulamentar e orientar a consolidação do SUS ${ }^{4,5}$.

Baseado em experiências pregressas de atuações positivas, com a de agentes de saúde nos estados do Paraná, do Mato Grosso do Sul e do Ceará, com o Programa de Agentes Comunitários de Saúde (PACS), em 1994, o Programa de Saúde da Família (PSF) foi lançado no âmbito nacional pelo MS como principal política de estruturação do SUS. Inicialmente concebido como programa, durante o seu desenvolvimento o PSF começou a perder esse caráter e passou a ser entendido como estratégia de reorganização do modelo de atenção à saúde e como alternativa de substituição do modelo dominante; em 1996 foi oficialmente descrito como Estratégia de Saúde da Família (ESF). Enquanto estratégia de reorganização da Atenção Básica, a ESF recebeu o desafio de reafirmar os princípios do SUS, com base em nova modelagem nas práticas profissionais ${ }^{3}$.

No que tange à promoção da saúde do idoso no território brasileiro, conta-se com algumas leis, decretos e portarias que, em linhas gerais, orientam a organização de serviços sociais e de saúde que possam contribuir para o envelhecimento saudável. Em janeiro de 1994 foi publicada a Lei 8.842 , que dispõe sobre a Política Nacional do Idoso (PNI), que em seu Capítulo IV, inciso II, prevê as ações governamentais para promover um envelhecimento saudável, quando, no item b, aponta a necessidade de "prevenir, promover e recuperar a saúde do idoso, mediante programas e medidas profiláticas"6.

Numa direção mais específica, em 1999, a Portaria $n^{\circ} 1.395$, de 10 de dezembro que regulamentou a Política Nacional de Saúde do Idoso (PNSI) sendo atualizada em outubro de 2006, por meio da Portaria no 2.528 , passando a chamar-se Política Nacional de Saúde da Pessoa Idosa (PNSPI). A partir daí, a atenção à saúde desse grupo etário passou a exigir das autoridades e dos profissionais de saúde um olhar mais específico, fato que culminou com a publicação $\mathrm{n}^{\circ} 19$ dos Cadernos de Atenção Básica à Saúde, que trata da promoção da saúde da pessoa idosa no âmbito da $\mathrm{ESF}^{7-10}$. 
Estudos realizados no campo da atenção à saúde da pessoa idosa indicam a necessidade de que os espaços de promoção da saúde para esse grupo etário considerem a pluralidade cultural que emerge das experiências contextuais. A ideia primordial é que a estruturação do processo de trabalho na ESF contribua para criar situações próximas da realidade na qual o idoso está inserido, de modo que estimule reflexões acerca da necessidade de ressignificar práticas, valores e atitudes.

Em nosso país, o cenário da velhice que se delineia para um futuro próximo, exige que as práticas de promoção da saúde do idoso sejam permeadas por situações que contribuam para prepará-lo para enfrentar várias realidades que se apresentarão no decorrer da vida, de maneira que tais práticas estejam pautadas num olhar crítico e emancipador, conduzindo-o para uma velhice bem-sucedida ${ }^{11}$.

As experiências em torno do processo de trabalho na ESF permitem caracterizá-lo como dinâmico, por permitir a remodelação constante das práticas; criativo, por suscitar possibilidades diferenciadas de intervenção; e democrático, ao propor o envolvimento do usuário, da família e da comunidade como corresponsáveis nas ações de promoção da saúde.

$\mathrm{Na}$ ESF, enquanto membro da equipe mínima, a enfermeira pode desenvolver atividades na unidade de saúde, como os procedimentos específicos de sua categoria profissional na assistência com ações voltadas para todos os grupos populacionais, como: Consulta de Enfermagem (CE), Visita Domiciliar (VD), participação em grupos na unidade ou na comunidade, atividades de apoio e supervisão ao trabalho do Agente Comunitário de Saúde (ACS) e do técnico ou auxiliar de enfermagem, podendo ainda assumir a gerência da unidade de saúde.

Especificamente na promoção da saúde da pessoa idosa, são atividades de competência da enfermeira: “a) Realizar atenção integral às pessoas idosas; b) Realizar assistência domiciliar, quando necessário; c) Realizar consulta de enfermagem, incluindo a avaliação multidimensional rápida e instrumentos complementares; se necessário, solicitar exames complementares e prescrever medicações, conforme protocolos ou outras normativas técnicas estabelecidas pelo gestor municipal, observando as disposições legais da profissão; d) Supervisionar e coordenar o trabalho do ACS e da equipe de enfermagem; e) Realizar atividades de educação permanente e interdisciplinar junto aos demais profissionais da equipe; f) Orientar ao ido- so, aos familiares e/ou cuidador sobre a correta utilização dos medicamentos" 10 .

Considerando a configuração sociopolítica do contexto no qual a ESF foi gestada, fica clara a necessidade de investir em práticas de saúde que contribuam para o deslocamento de ações centradas no corpo biológico para aquelas centradas nos corpos sociais. Enquanto prática social e historicamente constituída, o trabalho da enfermeira sempre teve o cuidado humano como núcleo de sua competência e a pessoa como foco de sua atuação, condições que favorecem a inserção de seu trabalho nessa estratégia.

$\mathrm{Na}$ ESF existem inúmeras possibilidades de que a atuação dos profissionais possa transpor a rigidez do trabalho hierarquizado e verticalizado, construindo possibilidades de melhor interação a partir de um planejamento horizontal, flexível e democrático, envolvendo toda a equipe e se deslocando para o usuário.

Nesse sentido, o presente texto teve como objetivo descrever a configuração do trabalho da enfermeira na atenção ao idoso na Estratégia de Saúde da Família.

\section{Método}

Trata-se de estudo exploratório-descritivo de abordagem qualitativa, cujo cenário foi a rede de atenção básica do município de Florianópolis, que conta com 49 Centros de Saúde (CSs) com ESF implantada, distribuídos em cinco distritos de saúde: Centro, Continente, Leste, Norte e Sul. A coleta de dados deste estudo ocorreu nos distritos sanitários do Centro e do Continente, por apresentarem maior número de pessoas idosas.

Participaram deste estudo 17 profissionais (16 enfermeiras e um enfermeiro) que desenvolvem atividades com o idoso. Para compor a amostra, a proposta do estudo foi apresentada em reunião mensal da categoria e, posteriormente, foi encaminhado convite via e-mail e realizado contato telefônico para agendamento da entrevista. A amostra foi composta pela quantidade de sujeitos que aceitaram participar do estudo, perfazendo $70 \%$ dos profissionais que atuavam na ESF durante os meses em que ocorreu a coleta.

A pesquisa obedeceu à Resolução 196/1996, que dispõe sobre as Diretrizes e Normas Regulamentares na Pesquisa com Seres Humanos. Submetida ao Comitê de Ética e Pesquisa com Seres Humanos da Universidade Federal de Santa Catarina, sendo aprovada ${ }^{12}$. 
A entrevista foi realizada no local de trabalho de cada informante com sua autorização. Ao concordar em participar de forma voluntária, leu e assinou o Termo de Consentimento Livre e Esclarecido (TCLE) em duas vias, sendo uma cópia do informante e outra da pesquisadora. Foi garantido à informante que os dados não seriam usados de forma indevida, respeitando-se a individualidade de cada um. Desse modo, optou-se por codificar cada informante com a letra E, da palavra "entrevista", seguida do número de ordem na sequência cronológica da entrevista.

A coleta de dados foi realizada durante os meses de fevereiro, março e maio de 2010, utilizando-se a técnica de entrevista narrativa, seguindo um roteiro com tópicos abertos sobre os quais as informantes deveriam discorrer com base em percepções e opiniões acerca de suas práticas cotidianas. As entrevistas foram gravadas e, depois de transcritas, encaminhadas aos informantes para validação ${ }^{13}$.

No que concerne às principais características das informantes, em relação à formação complementar à graduação, sete são especialistas em Saúde da Família e sete em áreas afins, sendo quatro em Saúde da Mulher, duas em Gerenciamento de Serviços de Saúde e três em Educação em Saúde; duas não referiram esse tipo de formação. De experiência profissional, o grupo tem em média 9,2 anos, variando entre 1 e 20 anos, e em relação ao tempo de atuação na ESF, a média de 2,5 anos, variando entre 1 e 11 anos. Das 17 informantes, 16 são efetivas e apenas uma tem relação empregatícia regida por contrato temporário.

Os resultados foram submetidos à técnica de Análise de Conteúdo (AC), que possibilitou resgatar elementos que descrevem o trabalho da enfermeira com o idoso na ESF. A AC obedeceu aos estágios de pré-análise, constituição do corpus, seleção das Unidades de Significância (US), classificação e agregação em núcleos temáticos, dando origem a três categorias e suas respectivas subcategorias: O cuidado individual: a consulta de enfermagem com o idoso (Consulta Centrada na Doença e Consulta Centrada no Idoso); O cuidado coletivo: a atuação em grupos (Grupos Internos e Grupos Externos); e O Cuidado no domicílio: a visita como espaço de atuação.

\section{Resultados e discussão}

A categoria $O$ cuidado individual: a consulta de enfermagem com o idoso englobou as US que abordaram o cuidado como ação exclusivamente di- recionada ao idoso, que se vem materializando na prática da enfermeira que atua na ESF, relacionando-o à Consulta de Enfermagem (CE) referida nas falas dos informantes como a ação de atender indivíduos em consultórios na unidade de saúde.

A CE se caracteriza como oportunidade de instituir uma relação de ajuda em busca por aprendizagens significativas que possam concorrer para o bem-estar das pessoas envolvidas, cujo objetivo final deve centrar-se na promoção da saúde. A CE está prevista na Lei $\mathrm{N}^{\circ} 7.498$, de 25 de junho de 1986, que regulamenta o exercício profissional da enfermeira no Brasil e no Decreto Regulamentador $\mathrm{N}^{\circ} 94.406$, de 8 de junho de 1987, no artigo 8, alínea "e"14,15.

Na mesma direção, a Portaria $N^{\circ} 1.625$, de 10 de julho de 2007, que alterou as atribuições dos profissionais das equipes de Saúde da Família contidas na Política Nacional de Atenção Básica (PNAB), em seu artigo $1^{\circ}$, alínea "II", dispõe sobre as ações privativas da enfermeira na Atenção Básica $(\mathrm{AB})$, incluindo a $\mathrm{CE}$ entre as demais atividades de competência dessa profissional. Convém salientar que as atividades a serem realizadas pela enfermeira na ESF, dispostas na PNAB, estão sujeitas às regulamentações por governos estaduais e municipais ${ }^{16}$.

Enquanto um dos instrumentos do processo de trabalho da enfermeira, a CE abrange um conjunto de ações que devem seguir uma sequência ordenada de atividades nas quais deve utilizar variadas técnicas com vistas a coletar informações que possibilitem "conhecer, compreender e explicar a situação de saúde" da pessoa para ter maior clareza e segurança quanto às recomendações necessárias, seja por meio de prescrição própria ou de encaminhamentos ${ }^{17}$.

As informantes deste estudo evidenciaram situações opostas nas quais a CE com o idoso se materializa na ESF: uma se reporta à CE centrada na doença e tem os programas de controle de hipertensão e de diabetes como espaços únicos de materialização, e outra na qual a CE é centrada no idoso, cujo atendimento é realizado no intuito de acompanhá-lo, independentemente de ter ou não um problema de saúde, conforme podemos observar no Quadro 1.

As US que compõem a subcategoria Consulta Centrada na Doença sugerem que a prática da enfermeira na ESF ainda tem suas ações fundamentadas no modelo biomédico, situação que não atende às recomendações contidas nos documentos oficiais que regulamentam a implantação e o funcionamento da ESF. 
Quadro 1. Distribuição dos discursos conforme categorias e subcategorias identificadas

Categoria 1. O cuidado individual: a consulta de enfermagem com o idoso

\begin{tabular}{|c|c|}
\hline Subcategorias & Unidades de Significância \\
\hline $\begin{array}{c}\text { Consulta } \\
\text { Centrada na } \\
\text { Doença }\end{array}$ & $\begin{array}{l}\text { Não temos agenda específica para consulta do idoso, temos vagas disponiveis nos } \\
\text { programas de controle da hipertensão e da diabetes. (E3) [...] marcamos consulta para } \\
\text { o idoso que é hipertenso ou diabético. (E4) Atendo o idoso nos programas de controle de } \\
\text { hipertensão e diabetes. (E10) Realizamos consulta de enfermagem a idosos nos } \\
\text { programas de controle de hipertensão e diabetes. (E11) A consulta de enfermagem é } \\
\text { para o portador de diabetes ou de hipertensão e tem muito idoso cadastrado no } \\
\text { Hiperdia. (E12) Realizamos consultas individuais com o idoso no atendimento ao } \\
\text { hipertenso e ao diabético [...]. (E14) Só recebemos os idosos para consultas nos } \\
\text { programas de Hipertensão e de Diabetes. (E16) [...] geralmente não é consulta do } \\
\text { idoso, é do hipertenso que é idoso, é do diabético que é idoso. (E17) }\end{array}$ \\
\hline $\begin{array}{l}\text { Consulta } \\
\text { Centrada no } \\
\text { Idoso }\end{array}$ & $\begin{array}{l}\text { Faço consulta de enfermagem direcionada ao idoso [...]. (E1) Estamos começando a } \\
\text { resgatar a consulta voltada para o idoso. (E2) Quando o paciente vem na primeira } \\
\text { consulta, eu sempre marco consultas intercaladas do médico e da enfermeira. (E5) [...] } \\
\text { fazemos consulta do idoso com aquele idoso que identificamos que precisa porque é uma } \\
\text { consulta que leva quase uma hora, e não são todos que precisam. (E6) [...] faço } \\
\text { consultas de enfermagem com o idoso. (E7) [...] também atendemos o idoso quando ele } \\
\text { não tem nenhuma doença, não é porque ele não é hipertenso ou diabético que não vai } \\
\text { ser atendido. (E8) O idoso está inserido no dia a dia da unidade, geralmente eles vêm } \\
\text { aqui para verificar a PA, isso é bem rotineiro e nós aproveitamos e já fazemos uma } \\
\text { consulta, abordando outros aspectos. (E15) }\end{array}$ \\
\hline
\end{tabular}

Desde 2006, o município onde ocorreu a coleta de dados vem implementando uma política específica de promoção da saúde do idoso, denominada Capital Idoso. Essa política surgiu da "finalidade primordial de promover, manter e recuperar a saúde, a autonomia e a independência da pessoa idosa, reduzir comorbidades e mortes prematuras, resultando, assim, em qualidade de vida para o idoso e familiar" ${ }^{18}$.

As linhas de ação contidas nessa política incluem: Gerontocultura, Assistência Clínica, Média Complexidade e Apoio ao Cuidador. Por ocasião da coleta de dados deste estudo, o protocolo em vigor para essa política não contemplava a CE com o idoso. Porém, nos demais programas, como o Hiperdia, a CE está prevista, situação que pode comprometer a atuação da enfermeira na promoção da saúde do idoso, uma vez que esse atendimento é destinado a monitorar as alterações das patologias englobadas pelo programa, cabendo ao profissional imprimir outras nuanças de intervenção.

Ao analisar o discurso de tal subcategoria, observa-se que a enfermeira atende ao idoso no Hiperdia com base em uma CE voltada para as queixas que ele apresenta, com uma proposta que focaliza a doença e não o ser humano. Em- bora se fale de saúde integral e no cuidado integrado na ESF, percebe-se que na prática ainda persiste um atendimento centrado na doença e, portanto, na proposta curativa, evidenciando as fragilidades do trabalho da enfermeira na ESF, além dos desafios para consolidar um espaço de atuação desse profissional no campo da saúde coletiva.

A dificuldade de se aproximar de práticas de promoção da saúde do idoso pode comprometer a estabilização e o avanço do trabalho da enfermeira na ESF, além de contribuir para fortalecer a cultura de deixar de promover saúde para continuar tratando de doentes.

Torna-se essencial que a enfermeira empreenda esforços para identificar e interpretar processos políticos nos quais sua inserção provoque mudanças com a utilização de metodologias de trabalho que auxiliem no redirecionamento das estratégias de cuidados com vistas a incentivar a adoção de atitudes positivas diante de doenças e condições crônicas de saúde, independentemente do grau de comprometimento da saúde do idoso.

Nessa categoria, verifica-se que algumas enfermeiras se afastam do referencial/paradigma da promoção da saúde ao investir na remodelação de suas práticas, pois ainda se mantêm fieis a 
modelos institucionalizados pela biomedicina, segmentando a atenção ao idoso por patologias. Essa situação pode implicar a estagnação das suas práticas, limitando suas possibilidades de contribuir com a construção dos conhecimentos na saúde coletiva, na área da enfermagem e com a consolidação dos princípios que regem a ESF e o SUS.

A relação assimétrica observada entre os dois núcleos temáticos dessa categoria indica possibilidades de consolidação de uma CE voltada para a promoção da saúde do idoso, conforme se observa nas falas da subcategoria Consulta Centrada no Idoso. As falas dos informantes guiam para a ideia de um atendimento que pretende caminhar em consonância com os discursos das políticas de promoção da saúde do idoso.

A CE voltada para promover a saúde do idoso na ESF deve proporcionar orientação de medidas adequadas objetivando estimular a adoção de posturas pertinentes com as necessidades peculiares desse grupo populacional. Desse modo, deve estar centrada em metodologias que estimulem continuamente a integração do idoso ao contexto familiar e social, premissa esta que vai ao encontro dos conteúdos das políticas de atenção ao idoso no Brasil.

As diretrizes políticas que regulamentam a atenção ao idoso indicam a necessidade de um modelo de atenção que contemple uma avaliação global, incluindo a investigação sistemática da história de vida do idoso, com ênfase nos problemas recorrentes nesse grupo populacional e direcionando a consulta para o problema identificado que deverá ser mais bem avaliado. Observa-se, no conjunto de falas sobre a CE centrada no idoso, que as enfermeiras reconhecem essa orientação e estão atuando de acordo com tais recomendações, quando referem que, por ser demorada, a CE ao idoso só é realizada com aqueles que precisam ${ }^{10}$.

Devido aos "modelos" de ESF que se vem estruturando no Brasil, a enfermeira deve apropriar-se de conhecimentos específicos e preservar os espaços nos quais possa realizar as ações recomendadas nos documentos oficiais, consolidando, assim, o seu campo de atuação nessa estratégia. Entende-se que uma $\mathrm{CE}$ voltada à promoção da saúde do idoso na ESF se constitui num valioso momento de interlocução profissional/usuário, por oferecer possibilidades de monitoramento das condições de saúde, permitindo a detecção precoce de problemas reais e potenciais. Desse modo, a enfermeira deve primar por uma CE que possa contribuir para uma assistência mais eficaz, conferindo melhor quali- dade ao atendimento e valor à sua categoria profissional.

O discurso da subcategoria Consulta Centrada no Idoso aponta para interpretações que se aproximam dos princípios da ESF. De um modo geral, as enfermeiras que estão conduzindo a $\mathrm{CE}$ para esse foco demonstram que estão buscando possíveis caminhos para atuar na promoção da saúde do idoso.

Nessa perspectiva, a CE deve ser entendida como "um processo de interação entre o profissional enfermeiro e o assistido, na busca da promoção da saúde, da prevenção de doenças e da limitação do dano" ${ }^{19}$. A CE com o idoso se caracteriza como uma das atividades previstas no campo da saúde coletiva e está incorporada à $\mathrm{PNAB}$ e à ESF com o objetivo de que a enfermeira possa abordar o paciente de forma integral contemplando suas necessidades reais e potenciais, bem como suas relações com os fatores condicionantes e determinantes da saúde e da doença, aproximando-se do ambiente dele.

Se por um lado a CE emergiu neste estudo como atividade estruturada e engessada pelas normas prescritas pelo MS, por outro verifica-se a concretização de atividades que inovam o processo de trabalho da enfermeira, contribuindo para construir práticas voltadas à promoção da saúde do idoso. A categoria O cuidado coletivo: a atuação em grupos englobou falas que retratam a atuação da enfermeira em grupos nos quais a ênfase das ações recai nas práticas de educação em saúde que se vêm materializando no interior da unidade de saúde, com a formação de grupos internos, cujos conteúdos discutidos são voltados para as patologias mais frequentes, e de grupos externos, que são os grupos de convivência de idosos, denominados pelos informantes deste estudo como "grupos comunitários". Nesses grupos, as enfermeiras desenvolvem atividades de forma pontual.

Os grupos de convivência integram o Programa Viver Ativo, da Secretaria Municipal de Assistência Social (SEMAS) de Florianópolis, por meio do Programa de Apoio aos Grupos de Convivência, que conta com 105 grupos cadastrados, dos quais 33 na Região Centro e 29 na Região Continente, locais de realização deste estudo ${ }^{20}$.

A estratégia de trabalho em grupo pode ser entendida como uma alternativa complementar ao tratamento tradicional, porque pode constituir-se numa esfera de atenção para além da clínica ao propor a problematização de questões que afetam os participantes a partir da socialização de seus relatos. 
Conceitualmente, o grupo pode ser compreendido "como um lócus que articula as várias dimensões da vida humana: social, porque aproxima, agrega, compartilha e/ou divide interesses e expectativas, constrói pessoas (sujeitos históricos), que constroem comunidades e estas, por sua vez, constroem os sujeitos; subjetiva, caracterizada pelos afetos, emoções, intelecto e cognição que também são conformados na realidade sócio-histórica da existência individual e coletiva das pessoas; e a biológica, que sintetiza no processo saúde/doença as múltiplas determinações constitucionais e genéticas, as relacionadas ao ambiente, além da atitude pessoal de cada um, na forma como interage com o meio interno, físico e psíquico, e externo"21.

Conforme se observa na subcategoria Grupos Internos, disposta no quadro abaixo, os grupos em funcionamento na unidade estão ligados às patologias que acometem o idoso, e alguns deles vinculam a dispensação do medicamento à frequência do idoso às reuniões. Essa modalidade de grupo integra e reforça as propostas do modelo biomédico, no qual a metodologia do trabalho grupal está ancorada numa proposta pedagógica considerada como tradicional (Quadro 2).

A estruturação de um grupo geralmente é guiada por situações comuns conforme se ob- serva nos discursos que compõem a subcategoria Grupos Internos, e deve buscar certa similaridade nas necessidades dos participantes com vistas a estimular o aprendizado com base nas experiências que eles socializam.

A formação de grupos por afinidade de problemas relacionados à saúde, por faixa etária e por interesses semelhantes, tem sido uma prática corriqueira na ESF, que se concretiza em consonância com o surgimento das demandas. "Na modalidade grupal o indivíduo tem a oportunidade de perceber que as pessoas vivenciam situações de saúde-doença com manifestações clínicas, angústias e preocupações parecidas" ${ }^{21}$. A identificação e o reconhecimento do seu problema no outro se destacam como fatores de maior adesão aos grupos.

Considerando a necessidade de buscar maior integração profissional/usuário, o trabalho com grupos desponta como valiosa estratégia nessa direção. Entretanto, é preciso compreender que a busca pela superação das práticas instituídas no modelo tradicional deve estar atrelado ao trabalho com grupos na ESF.

Desse modo, a orientação é que, mesmo se tratando de um grupo voltado para idosos com determinadas patologias, o foco do trabalho seja permeado pela problematização das situações

Quadro 2. Distribuição dos discursos conforme categorias e subcategorias identificadas

Categoria 2. O cuidado coletivo: a atuação em grupos

\begin{tabular}{|c|l|}
\hline Subcategorias & \multicolumn{1}{c|}{ Unidades de Significância } \\
\hline \multirow{1}{*}{ Grupos } & {$[\ldots]$ temos grupos de idosos voltados para idosos portadores de doenças crônicas. (E5) } \\
& {$[\ldots]$ temos grupos para idosos com diabetes e hipertensão [...]. (E7) Têm os grupos } \\
& específicos de hipertensos e diabéticos que tem muito idoso. (E8) [...] estamos iniciando \\
a formação de um grupo de hipertensos, diabéticos e idosos [...]. (E9) Temos um grupo \\
de hipertensos e diabéticos que é coordenado por uma das enfermeiras daqui e tem \\
muito idoso [...]. (E10) Aqui na unidade tem um grupo de hipertensos e diabéticos e \\
esse tem uma grande participação, porque é um dos requisitos para que o paciente \\
receba a fita para realização da glicemia para fazer o teste em casa. (E12)
\end{tabular}


que cotidianamente influenciam o processo de viver dos participantes, estimulando inclusive a socialização das conquistas pessoais de cada com base nas mudanças de hábitos impostas pelas doenças.

De forma assimétrica, o discurso que emerge da subcategoria Grupos Externos aparece como fator de facilitação para o trabalho da enfermeira na ESF, pois são constituídos e funcionam com apoio da Secretaria Municipal de Assistência Social (SMAS) local, totalmente independentes da unidade, constituindo-se em organizações sociais espontâneas, com a finalidade de criar espaços para cultivar a sociabilidade entre idosos.

Devido a essa questão, nem todos os informantes desenvolvem um trabalho regular nesses grupos. Entretanto, o fato de alguns buscarem aproximar-se deles demonstra importante iniciativa na busca por novos espaços de inserção de sua prática profissional, uma vez que favorece a interlocução do seu trabalho com os equipamentos sociais disponíveis na área de abrangência da ESF na qual atua.

A inserção do trabalho da enfermeira nos grupos de convivência pode contribuir na efetivação de ações de promoção da saúde do idoso à medida que buscar agregar práticas de intervenção ao perfil de necessidades dos membros do grupo por meio de um processo educativo que possa estimular a aproximação e convivência das pessoas, contribuindo com o fortalecimento das potencialidades individuais e grupais na valorização da saúde, na utilização dos recursos disponíveis e no exercício da cidadania ${ }^{22}$.

O grupo pode representar um agente facilitador do exercício de independência e de autonomia pelo fato de funcionar como uma rede de apoio que mobiliza as possibilidades de resgate da autoestima e o acesso a informações oportunas acerca de questões peculiares ao processo de envelhecimento, aspectos importantes na redução das vulnerabilidades a partir de ações de prevenção.

A tendência atual é de que, com o envelhecimento populacional crescente, a redução do tamanho das famílias e a necessidade de promover a inserção social constante do idoso, os grupos de convivência, enquanto política de incentivo à socialização, sejam cada vez mais ampliados na sociedade brasileira.

Mesmo que os grupos de idosos clamem por uma intervenção multiprofissional, a enfermeira deve envidar esforços para identificar e afirmar seu espaço de intervenção no trabalho com grupos de idosos de modo a contribuir para a consolidação dessa importante atividade no âmbito na ESF.
Considerando a variabilidade de ações implementadas nos grupos de convivência de idosos, é natural que a enfermeira encontre resistências internas para desenvolver um trabalho específico de promoção da saúde, daí a necessidade de inseri-la no grupo com vínculo mais contínuo e não ocasional, de modo que possa integrar ações mais específicas à proposta de trabalho do grupo sem interrupção.

$\mathrm{Na}$ realidade, participando mais efetivamente, a enfermeira poderá identificar os espaços nos quais discussões acerca da saúde podem ser introduzidas nas rotinas dos grupos de convivência. O fato de buscar a correlação das atitudes e posturas que determinam e condicionam os problemas de saúde dos membros do grupo pode despontar como uma rica possibilidade de direcionar debates nesse campo, em vez de realizar trabalhos pontuais por ocasião das campanhas propostas pelas diversas instâncias políticas.

A terceira categoria, denominada de $\mathrm{O}$ Cuidado no domicílio: a visita como espaço de atuação, evidencia um discurso no qual observa-se que a visita domiciliar vem constituindo-se como um espaço para que a enfermeira desenvolva ações de promoção da saúde do idoso de forma integral, ao se preocupar em acessar informações necessárias para a prevenção de problemas reais e potenciais, conforme podemos observar no Quadro 3.

A realização da Visita Domiciliar (VD) pela enfermeira no Brasil foi introduzida em 1918, quando Carlos Chagas, diretor do Departamento Nacional de Saúde Pública, incentivou a criação de cursos e escolas, entre elas a de Enfermeiras Visitadoras, fundada com apoio da Fundação Rockfeller em $1923^{23}$.

Historicamente, a VD tem-se caracterizado como importante estratégia de intervenção dos profissionais de saúde, considerando as possibilidades de aproximação do contexto social e familiar, incluindo as questões objetivas e subjetivas que contribuem para o adoecimento.

Com a implantação da ESF, a VD é reintroduzida como estratégia de atuação coletiva, na qual os profissionais de saúde podem priorizar situações que necessitam de olhares específicos, mas totalizadores. Como um dos instrumentos da intervenção da enfermagem no campo da saúde pública, a VD tem a família como alvo de sua atenção e pode ser conceituada como "um conjunto de ações com aspectos educativos que traz em seu bojo atuações que priorizam orientações para o autocuidado, manutenção e promoção da saúde, monitoramento dos agravos, situações 
Quadro 3. Distribuição dos discursos conforme categoria identificada.

Categoria 3. O Cuidado no domicílio: a visita como espaço de atuação

$\mathrm{Na}$ visita questionamos sobre o uso do medicamento, hábitos de vida, sobre alimentação, hidratação, eliminações. (E1) [...] verifico as condições em que ele vive, verificamos $P A$, fazemos controle de glicemia, orientamos sobre alimentação, sobre higiene e cuidados gerais. (E3) Faço uma abordagem mais ampla e direciono para a questão da patologia que ele tem. (E5) [...] observo o ambiente, a higiene, se o local onde ele dorme é arejado, se bate sol, se tem ventilação, vejo o estado geral dele, verifico sinais vitais [...]. (E8) [...] observo as relações dele com a família, com o cuidador. (E10) [...] fazemos

Unidades de Significância uma abordagem integral, desde questões sobre medicamentos, alimentação, higiene, estado geral, moradia, aspectos familiares e a equipe sempre foca na educação em saúde, visando à melhoria da qualidade de vida. (E11) [...] avalio o estado geral, faço exame físico, sigo todos os passos da consulta de enfermagem. (E12) [...] avalio o ambiente, o contexto, observo as pessoas que moram na casa, as pessoas que estão ao lado. (E13) [...] avalio as condições gerais do paciente, pele, higiene, aparência, vejo se está sendo bem cuidado, até para evitar a formação de escaras, oriento sobre a movimentação, mudança de posição, banho de sol. (E15) específicas, temporárias ou não, e acompanhamento das situações presentes nos contextos familiar e social" 24 .

Com a reorientação do modelo de atenção à saúde preconizado pelo SUS e a adoção da ESF como principal política da atenção básica, a VD pode ser apontada como um eixo transversal às demais ações de promoção da saúde, que contribui para uma atenção mais universal, integral e com equidade.

Desse modo, como ação essencial em seu leque de atividades, a ESF resgata a prática da VD como atividade comum a todos os membros da equipe, resguardando a competência de cada um em relação às necessidades do usuário e da família que carecem da visita.

Vários são os fatores que levam os entrevistados a realizarem a VD, indo desde um número elevado de idosos acamados ou semiacamados que não podem ir à unidade, até as questões geográficas das áreas de abrangência das unidades de saúde, que, por estarem localizadas em áreas de morro, na maioria das vezes se tornam de difícil acesso para o idoso, devido ao grande número de ladeiras e degraus no percurso.

No intuito de consolidar sua atuação no campo da saúde coletiva, o resgate da VD emerge como importante instrumento de intervenção da enfermeira, pois, conforme se observa no discurso dessa categoria, é a oportunidade de realizar uma CE integral e abrangente, considerando que no domicílio, além de avaliar o idoso, olha para questões que determinam e condicionam o processo saúde/doença.
A prática da VD pela enfermeira no campo da saúde coletiva emerge como oportunidade ímpar para executar ações direcionadas ao indivíduo inserido na família e na comunidade, situação que se reforçou com a implantação da ESF, que incentiva as ações extramuros como imprescindíveis para intervir no processo saúde/doença da população.

Neste estudo, a VD ao idoso despontou como importante espaço de atuação da enfermeira, em virtude da melhor aceitabilidade pela demanda e das inúmeras possibilidades de desenvolver ações que concorram para o controle de causas, de riscos e de danos que podem comprometer o bemestar do paciente, demonstrando ser um instrumento essencial no processo de trabalho na ESF.

\section{Conclusão}

Considerando a dinamicidade que os profissionais de saúde devem imprimir ao processo de trabalho na ESF, percebe-se a necessidade de redefinir as concepções acerca da promoção da saúde. Para a enfermeira está posto o desafio de rever sua prática, repensar os modos de operar o trabalho e desenvolver metodologias e instrumentos com base em conhecimentos socialmente instituídos.

O fato de existirem contradições na dinâmica do trabalho da enfermeira no âmbito da ESF pode servir como convite à reflexão a respeito das possibilidades de conquistar e demarcar seu espaço de atuação no campo da saúde coletiva. 
Acreditamos que, durante o atendimento ao idoso, torna-se essencial que as ações da enfermeira sejam permeadas pela compreensão de que o envelhecimento se caracteriza por alterações específicas, exigindo habilidades profissionais para lidar com a diversidade de situações apresentadas por essa demanda, levando em conta os direitos e deveres da pessoa idosa, bem como sua experiência de vida acumulada.

O lidar cotidiano com o idoso no âmbito da ESF deve buscar a superação do olhar biomédico centrado nas queixas, partindo para o entendimento de saúde como resultado das condições de vida, conforme disposto na Constituição Federal.

Desse modo, notamos que o foco da atenção não deve prender-se apenas aos problemas e às dificuldades, mas também e, sobretudo, às potencialidades, valorizando o complexo sociocultural de aprendizagem ao longo da vida do paciente. A atenção à saúde do idoso, na perspectiva de fornecer subsídios para um envelhecimento saudável em conformidade com as diretrizes políticas no âmbito nacional e mundial, constituise num desafio a ser incorporado ao processo de trabalho das equipes da ESF.

É importante compreender que a ESF deve possibilitar maior aproximação com a população adscrita de forma que a equipe possa perceber os condicionantes e os determinantes envolvidos no processo saúde/doença individual e coletivamente. No que tange à atenção à pessoa idosa, a enfermeira deve primar por ações que con- tribuam para promover a saúde e o bem-estar e para prevenir e controlar problemas decorrentes das doenças prevalentes na velhice e, consequentemente, consolidar o processo de trabalho dessa categoria profissional com a sistematização de suas ações.

Portanto, é necessário que o trabalho da equipe da ESF se volte para a criação de alternativas de promover saúde, cujos princípios se pautem na visão integral do indivíduo e da família com o intuito de facilitar a aproximação usuário/equipe/ serviço de saúde, incentivando o desenvolvimento de ações de corresponsabilização. O trabalho dos profissionais da ESF deve priorizar a atenção integral à saúde do indivíduo nas várias fases do ciclo vital considerando o cenário familiar e social.

Independentemente da função que ocupa, a enfermeira deve buscar o desenvolvimento de ações condizentes com o perfil da população adscrita, operando processos de trabalho que possibilitem o aperfeiçoamento contínuo do pessoal que está sob sua supervisão, visando à manutenção das condições para um cuidado mais eficiente.

Observa-se que, mesmo desenvolvidas em momentos diferenciados, as atividades da enfermeira na atenção ao idoso estão interligadas e são interdependentes. Todas elas são realizadas a partir de uma programação pontual, com base na análise das condições da população em acessar ou não a unidade, da disponibilidade da profissional e do apoio logístico da Secretaria Municipal de Saúde.

\section{Colaboradores}

GML Pinheiro, AM Alvarez e DEP Pires participaram igualmente de todas as etapas de elaboração do artigo. 


\section{Referências}

1. Brasil. Ministério da Saúde. Reatório final. Documentos da VIII Conferência Nacional da Saúde; 1986 Mar 17-21; Brasília, DF, MS; 1986.

2. Constituição da República Federativa do Brasil. In: Oliveira J, organizador. Série Legislação Brasileira. São Paulo: Saraiva; 1989.

3. Viana NAD, Dal Poz MR. A reforma do sistema de saúde no Brasil e o PSF. Rev Physis 2005; 15(Supl.): 225-264.

4. Brasil. Lei Orgânica da Saúde. Lei no 8.080, de 19 de setembro de 1990. Dispõe sobre as condições para a promoção, proteção e recuperação da saúde, a organização e o funcionamento dos serviços correspondentes e dá outras providências. Diário Oficial da União 1990; 20 set.

5. Brasil. Lei no 8.142 , de 28 de dezembro de 1990. Dispõe sobre a Participação da Comunidade na Gestão do Sistema Único de Saúde (SUS) e sobre as Transferências Intergovernamentais de Recursos Financeiros na Área da Saúde e dá Outras Providências. Diário Oficial da União 1990; $31 \mathrm{dez}$.

6. Brasil. Lei $\mathrm{n}^{\circ} 8.842$, de 4 de janeiro de 1994. Dispõe sobre a Política Nacional do Idoso, cria o Conselho Nacional do Idoso e dá outras providências. Diário Oficial da União 1994; 5 jan.

7. Brasil. Ministério da Saúde (MS). Portaria n. ${ }^{\circ}$ 1.395/ GM, de 10 de dezembro de 1999. Aprova a Política Nacional de Saúde do Idoso. Brasília: MS; 1999.

8. Brasil. Ministério da Saúde (MS). Portaria no 2.528, de 19 de outubro de 2006. Aprova a Política Nacional de Saúde da Pessoa Idosa. Brasília: MS; 2006.

9. Brasil. Ministério da Saúde (MS). Política Nacional de Atenção Básica. Brasília: MS; 2006.

10. Brasil. Ministério da Saúde (MS). Cadernos de Atenção Básica à Saúde - no 19. Brasília: MS; 2006.

11. Both A. Longevidade e educação: fundamentos e práticas. In: Freitas EV, Py L, organizadores. Tratado de Geriatria e Gerontologia. Rio de Janeiro: Guanabara Koogan, 2006. p. 1446-1455.

12. Brasil. Ministério da Saúde (MS). Resolução 196/96. Diretrizes e Normas Regulamentadoras de Pesquisas Envolvendo Seres Humanos. Brasília: MS; 1996.

13. Bardin L. Análise de conteúdo. Lisboa: Edições 70; 2009.

14. Brasil. Lei $n^{\circ} 7.498$, de 25 de junho de 1986. Dispõe sobre a regulamentação do exercício da enfermagem e dá outras providências. Diário Oficial da União 1986; 26 jun.
15. Brasil Decreto no 94.406 , de 08 de junho de 1987. Regulamenta a Lei no 7.498 , de 25 de junho de 1986, que dispõe sobre o exercício da enfermagem, e dá outras providências. Diário Oficial da União 16. 1987; 09 jun.

Brasil. Portaria no 1.625, de 10 de julho de 2007. Altera as atribuições dos profissionais das Equipes de Saúde da Família (ESF), dispostas na Política Nacional de Aten-

17. ção Básica. Diário Oficial da União 2007; 11 jul. Vanzin AS, Nery MES. Consulta de enfermagem: uma necessidade social? Porto Alegre: RM\&L Gráfica;

18. 1996.

Florianópolis. Secretaria Municipal de Saúde. Programa de Saúde do Idoso - Capital Idoso. No prelo

19. 2010.

Machado MT, Leitão GCM, Holanda FUX. O conceito de ação comunicativa: uma contribuição para a consulta de enfermagem. Rev Latino-Am Enfer-

20. magem. 2005; 13(5):723-728.

Florianópolis. Secretaria Municipal de Assistência Social. Programa Viver Ativo. [acessado 2010 out

21. 12]. Disponível em: http://portal.pmf.sc.gov.br/. Alonso ILK. O processo educativo em saúde na dimensão grupal. Texto contexto - enferm. 1999;

22. 8(1):122-132.

Sobreira NR. Enfermagem comunitária. Rio de ja-

23. neiro: Interamericana; 1981.

Drulla AG, Alexandre AMC, Rubel FI, Mazza VA. A visita domiciliar como ferramenta ao cuidado

24. familiar. Cogitare Enferm 2009; 14(4):667-674. Silva MA, Oliveira AGB, Mandú ENT, Marcon SR. Enfermeiro \& grupos em PSF: possibilidade para participação social. Cogitare Enferm 2006; 11(2):143149.

Artigo apresentado em 11/07/2011

Aprovado em 16/10/2011

Versão final apresentado em 22/10/2011 